\title{
The first autochthonous case of feline ocular thelaziosis in Austria
}

\author{
Adnan Hodžić ${ }^{1}$ (D) Albert Payer ${ }^{2} \cdot$ Georg Gerhard Duscher $^{1}$
}

Received: 18 January 2019 / Accepted: 20 February 2019 / Published online: 2 March 2019

(C) The Author(s) 2019

\begin{abstract}
Over the last 30 years, Thelazia callipaeda (Spirurida: Thelaziidae) has increasingly been reported as an agent of ocular infections in animals and humans throughout Europe. Following the cases of canine ocular thelaziosis recently recorded in Austria for the first time, in the present paper, we describe the first case of T. callipaeda infection in an Austrian cat with no history of traveling abroad. This finding further supports the occurrence of the parasite's autochthonous transmission cycle in the country. The cat showed serous ocular discharge, conjunctival hyperemia, and mild conjunctival edema in the right eye. Mechanical removal of the parasite from the cat's eye, in combination with milbemycin oxime/ praziquantel oral treatment and topical use of tobramycin/dexamethasone eye drops led to complete resolution of the clinical signs within 2 weeks. Results presented in the current study are of great importance for the local veterinarians who seemed largely unaware of this zoonotic parasite. Therefore, increased awareness of medical and veterinary communities is imperative for preventing further infections in both animals and humans.
\end{abstract}

Keywords Austria $\cdot$ Cat $\cdot \operatorname{cox} 1 \cdot$ Haplotype $1 \cdot$ Thelazia callipaeda

\section{Introduction}

Thelazia callipaeda (Spirurida, Thelaziidae) is a vectorborne nematode of veterinary and medical concerns inhabiting the conjunctival sac and associated ocular tissues of domestic and wild carnivores, lagomorphs, and humans (Otranto et al. 2009, 2015). This zoonotic parasite is capable to induce a variety of clinical signs in the infected hosts, ranging from asymptomatic carriage to mild and severe ocular pathology that includes, e.g., epiphora, blepharitis, conjunctivitis, and keratitis (Otranto and Traversa 2005). In Europe, T. callipaeda is transmitted by male Phortica variegata (Drosophilidae, Steganinae) drosophilids, which deposit infective third-stage larvae while feeding on ocular secretions of the hosts (Otranto

Section Editor: Domenico Otranto

Adnan Hodžić

adnan.hodzic@vetmeduni.ac.at

1 Institute of Parasitology, Department of Pathobiology, University of Veterinary Medicine Vienna, Veterinaerplatz 1, 1210 Vienna, Austria

2 Tierklinik Deutschlandsberg, Erlenweg 6, 8530 Deutschlandsberg, Austria et al. 2006a). Because the nematode originally occurred in the Far Eastern countries, it has often been referred to as "oriental eye worm" (Máca and Otranto 2014). However, since the first European case of canine ocular thelaziosis was described in Italy in 1989 (Rossi and Bertaglia 1989), T. callipaeda has increasingly been reported in animals from France (Dorchies et al. 2007), Switzerland (Malacrida et al. 2008), Germany (Magnis et al. 2010), Spain (Miró et al. 2011), Portugal (Vieira et al. 2012), Bosnia and Herzegovina (Hodžić et al. 2014), Croatia (Hodžić et al. 2014), Serbia (Gajić et al. 2014), Romania (Mihalca et al. 2015), Bulgaria (Colella et al. 2016), Hungary (Colella et al. 2016), Slovakia (Čabanová et al. 2017), and Greece (Diakou et al. 2015; Papadopoulos et al. 2018) (Fig. 1). The zoonotic potential of this nematode has been confirmed by several human cases recorded in endemic regions of Europe (Otranto and Dutto 2008; Fuentes et al. 2011; Tasić-Otašević et al. 2016; Paradžik et al. 2016) (Fig. 1).

Canine infections caused by $T$. callipaeda have recently been described in Austria for the first time, with only five cases reported by the local veterinarians over the last 5 years (Hinney et al. 2016). Three of the cases were presumably autochthonous since the dogs likely had never left the country. In this paper, we describe the first case of feline ocular thelaziosis due to T. callipaeda in Austria. 


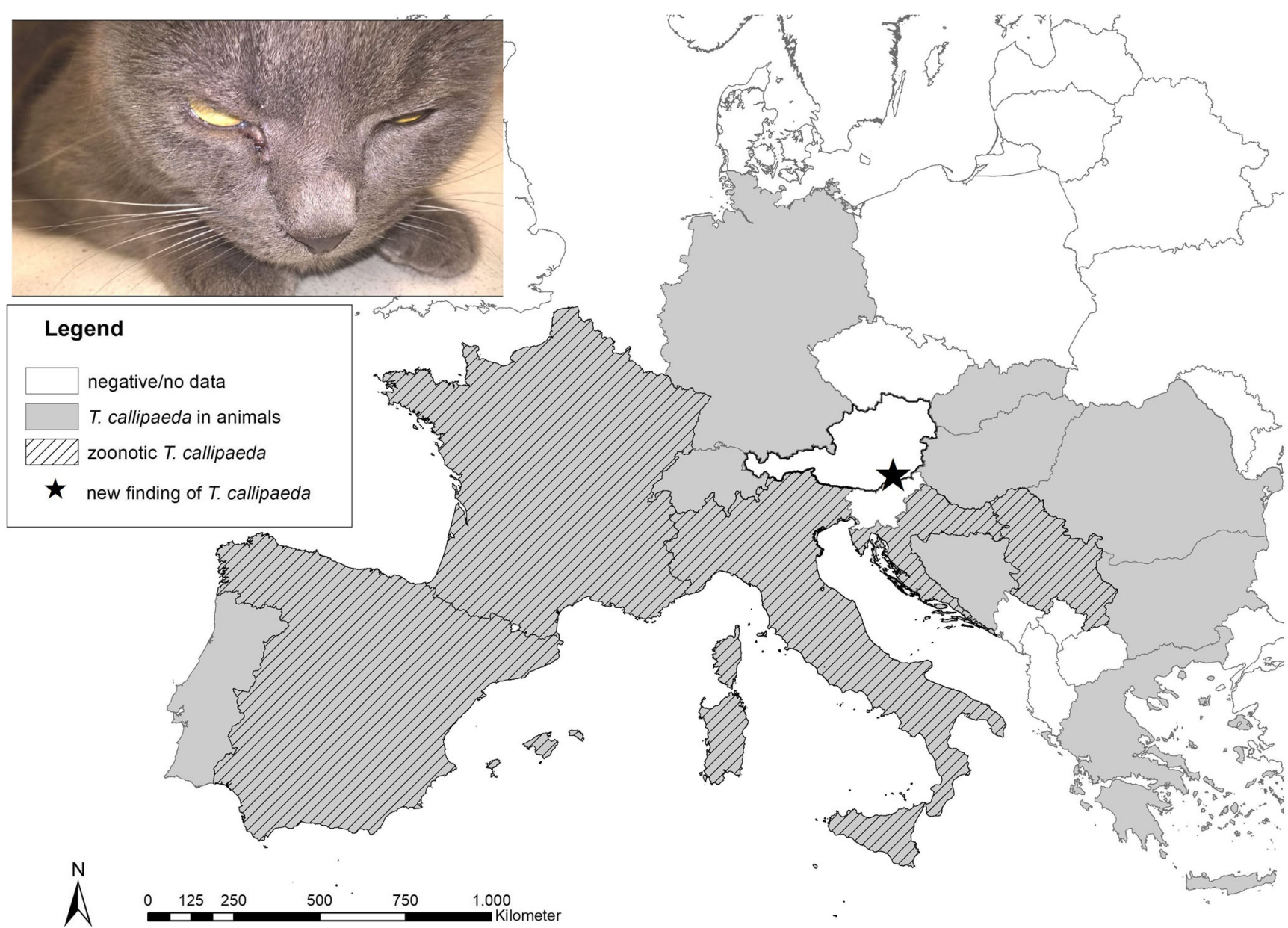

Fig. 1 A map showing the distribution of known cases of Thelazia callipaeda infections in Europe. Black star indicates the location where the infected cat in Austria was found

\section{Case report}

In November 2018, a six-year-old neutered male European shorthair cat, suffering from chronic conjunctivitis of the right eye, was referred to its local veterinary clinic in Deutschlandsberg, Austria (coordinates, $46^{\circ} 48^{\prime} 58^{\prime \prime} \mathrm{N}, 15^{\circ} 12^{\prime}$ 54" E) (Fig. 1). According to anamnestic data, first signs of ocular disease appeared 4-5 weeks before the cat was brought to the clinic. Ophthalmological examination revealed unilateral serous ocular discharge, conjunctival hyperemia, and mild conjunctival edema. Additionally, a thread-like motile worm was noticed under the nictitating membrane of the right eye. No other ocular abnormalities were detected. The parasite was retrieved using a forceps, placed in a tube with saline solution and sent to the Institute of Parasitology, University of Veterinary Medicine Vienna for morphological and molecular identification.

After removing the parasite, the cat was orally treated with milbemycin oxime $2 \mathrm{mg} / \mathrm{kg}$ and praziquantel $5 \mathrm{mg} / \mathrm{kg}$ (Milbemax ${ }^{\circledR}$, Novartis Animal Health, France). In addition, tobramycin $3 \mathrm{mg} / \mathrm{ml}$ and dexamethasone $1 \mathrm{mg} / \mathrm{ml}$ eye drops (Tobradex ${ }^{\circledR}$, Alcon Ophthalmika, Austria) were administrated twice a day in a 7-day treatment course. At a follow-up 2 weeks after the treatment, complete resolution of clinical signs was observed and no parasites were detected.

The nematode was identified as a female of $T$. callipaeda based on the specific morphological features (e.g., striated cuticula, hexagonal oral opening, vulva located anteriorly to the esophageal-intestinal junction, uterus filled with larvated eggs) (Otranto et al. 2004a). Species identity was further confirmed by PCR amplification and sequencing of the cytochrome $c$ oxidase subunit 1 ( $\operatorname{cox} 1)$ gene (Otranto et al. 2005). Nucleotide sequences derived from the adult nematode displayed $100 \%$ identity to the cox 1 sequences of T. callipaeda haplotype-1 (GenBank ${ }^{\circledR}$ accession no. AM042549), which is the only haplotype circulating among animals and humans in Europe.

\section{Discussion}

Following the recent reports of canine thelaziosis in Austria (Hinney et al. 2016), the current study describes the first case 
of $T$. callipaeda infection in a cat that never traveled abroad, further supporting the existence of autochthonous transmission cycle in the country.

However, the way(s) how this parasite was initially introduced to Austria remains unknown. One of the possible explanations is that $T$. callipaeda could have arrived via pet traveling, illegal pet trade or import/export of stray dogs, usually coming from endemic regions of Eastern Europe. These have often been indicated as efficient routes for transmission and spread of zoonotic parasites from endemic to nonendemic areas (Graham-Brown et al. 2017). For instance, three cases of imported $T$. callipaeda infections had recently been described in dogs from the United Kingdom that traveled to the countries in Europe where the parasite is highly prevalent (Graham-Brown et al. 2017).

Furthermore, the geographical expansion of T. callipaeda to non-endemic areas has also been linked to the migration of infected wild carnivores, in particular foxes, which seem to play an important role as reservoirs of T. callipaeda in Europe (Otranto et al. 2009; Hodžić et al. 2014; Mihalca et al. 2016). This is also a plausible scenario which could explain the introduction of the eye worm to Austria. Therefore, future studies should be focused on wild animals in order to assess the role they play in the ecoepidemiology of this zoonotic parasite.

Thelazia callipaeda is a vector-borne nematode and thus its distribution is expected to overlap with dispersion range of the fruit fly $P$. variegata, the only known vector of this nematode in Europe (Máca and Otranto 2014). However, the introduction of the parasite from abroad by the vector seems to be less likely because fruit flies are not able to travel over long distances (Ruytoor et al. 2010). To the best of our knowledge, the occurrence of $P$. variegata has not yet been confirmed in Austria. Meanwhile, the ecological niche model, used to predict the distribution of this fruit fly, showed that large areas of Austria, including the place where the infected cat was found, is environmentally suitable for the development of $P$. variegata and consequently for establishing endemicity (Otranto et al. 2006b; Palfreyman et al. 2018). The infected cat was living indoor, with regular outdoor access, in a rural area characterized by many vineyards and wildlife species richness, which represents the typical environment requested by the parasite to complete its life cycle. Moreover, the cat from the presented case was referred to the veterinary clinic in November, but it displayed signs of ocular discomfort a month before that. Considering the parasite requires several weeks to reach the adult stage (Otranto et al. 2004b, 2005), which is mostly responsible for causing clinical signs of the infection, it could be presumed that the animal acquired the parasite in summer (July-August) when the vector activity is at the highest level (Otranto et al. 2006a, b). In any case, it is reasonable to expect more cases of ocular thelaziosis in the following years and its further expansion to new areas in Austria, as recently demonstrated in a study conducted in Spain (Marino et al. 2018).
Treatment of $T$. callipaeda infection includes mechanical removal of the worms and administration of macrocyclic lactones. Oral milbemycin oxime/praziquantel and milbemycin oxime/afoxolaner combinations (Motta et al. 2012; Lebon et al. 2019), as well as moxidectin/imidacloprid spot-on formulation (Otranto et al. 2016, 2019) showed high therapeutic efficacy in naturally infected dogs and cats. Milbemycin oxime/ praziquantel treatment should be given twice in an interval of 7 days (Motta et al. 2012), whereas a single treatment of moxidectin/imidacloprid and milbemycin oxime/afoxolaner is found to be sufficient for complete parasite elimination (Otranto et al. 2016, 2019; Lebon et al. 2019). Moreover, the monthly administration of the abovementioned anthelmintic products can be used as a prophylactic treatment (Motta et al. 2012; Otranto et al. 2016, 2019; Lebon et al. 2019). In this study, mechanical removal of the parasite followed by oral administration of milbemycin oxime/praziquantel led to complete resolution of the associated clinical signs in 2 weeks.

Results presented in the current study are of great importance for the local veterinarians who seemed largely unaware of this zoonotic parasite. Therefore, increased awareness of medical and veterinary communities should help to prevent further infections in animals and humans.

Acknowledgements We would like to thank Walpurga Wille-Piazzai (Institute of Parasitology, University of Veterinary Medicine Vienna) for her excellent technical support.

Funding information Open access funding provided by University of Veterinary Medicine Vienna.

\section{Compliance with ethical standards}

Conflict of interest The authors declare there are no conflicts of interest.

Ethical statement All medical procedures were carried out by an experienced veterinarian and in accordance with the current national animal welfare requirements (BGBL. I Nr. 118/2004). Informed consent was obtained from the owner of the animal.

Open Access This article is distributed under the terms of the Creative Commons Attribution 4.0 International License (http:// creativecommons.org/licenses/by/4.0/), which permits unrestricted use, distribution, and reproduction in any medium, provided you give appropriate credit to the original author(s) and the source, provide a link to the Creative Commons license, and indicate if changes were made.

Publisher's note Springer Nature remains neutral with regard to jurisdictional claims in published maps and institutional affiliations.

\section{References}

Čabanová V, Kocák P, Víchová B, Miterpáková M (2017) First autochthonous cases of canine thelaziosis in Slovakia: a new affected area in Central Europe. Parasit Vectors 10:179 
Colella V, Kirkova Z, Fok É, Mihalca AD, Tasić-Otašević S, Hodžić A, Dantas-Torres F, Otranto D (2016) Increase in eyeworm infections in Eastern Europe. Emerg Infect Dis 22:1513-1515

Diakou A, Di Cesare A, Tzimoulia S, Tzimoulias I, Trvaersa D (2015) Thelazia callipaeda (Spirurida: Thelaziidae): first report in Greece and a case of canine infection. Parasitol Res 114:2771-2775

Dorchies P, Chaudieu G, Siméon LA, Cazalot G, Cantacessi C, Otranto D (2007) First reports of autochthonous eyeworm infection by Thelazia callipaeda (Spirurida, Thelaziidae) in dogs and cat from France. Vet Parasitol 149:294-297

Gajić B, Bogunović D, Stevanović J, Kulišić Z, Simeunović P, Stanimirović Z (2014) Canine and feline thelaziosis caused by Thelazia callipaeda in Serbia. Acta Vet-Beogr 64:447-455

Graham-Brown J, Gilmore P, Colella V, Moss L, Dixon C, Andrews M, Arbeid P, Barber J, Timofte D, McGarry J, Otranto D, Williams D (2017) Three cases of imported eyeworm infection in dogs: a new threat for the United Kingdom. Vet Rec 181:346

Hinney B, Fuehrer HP, Hodžić A, Joachim A (2016) Thelazia callipaeda in dogs from Austria (abstract in German). Tagung der DVGFachgruppe "Parasitologie und parasitäre Krankheiten", 2-6 May, 2016, Berlin, Germany

Hodžić A, Latrofa MS, Annoscia G, Alić A, Beck R, Lia RP, DantasTorres F, Otranto D (2014) The spread of zoonotic Thelazia callipaeda in the Balkan area. Parasit Vectors 7:352

Lebon W, Guillot J, Álvarez MJ, Antonio Bazaga J, Cortes-Dubly ML, Dumont P, Eberhardt M, Gómez H, Pennant O, Siméon N, Beugnet F, Halos L (2019) Prevention of canine ocular thelaziosis (Thelazia callipaeda) with a combination of milbemycin oxime and afoxolaner (Nexgard spectra ${ }^{\circledR}$ ) in endemic areas in France and Spain. Parasite 26:1

Máca J, Otranto D (2014) Drosophilidae feeding on animals and the inherent mystery of their parasitism. Parasit Vectors 7:516

Magnis J, Naucke TJ, Mathis A, Deplazes P, Schnyder M (2010) Local transmission of the eye worm Thelazia callipaeda in southern Germany. Parasitol Res 106:715-717

Malacrida F, Hegglin D, Bacciarini L, Otranto D, Nägeli F, Nägeli C, Bernasconi C, Scheu U, Balli A, Marenco M, Togni L, Deplazes P, Schnyder M (2008) Emergence of canine ocular thelaziosis caused by Thelazia callipaeda in southern Switzerland. Vet Parasitol 157: 321-327

Marino V, Gálvez R, Colella V, Sarquis J, Checa R, Montoya A, Barrera JP, Domínguez S, Lia RP, Otranto D, Miró G (2018) Detection of Thelazia callipaeda in Phortica variegata and spread of canine thelaziosis to new areas in Spain. Parasit Vectors 11:195

Mihalca AD, D'Amico G, Scurtu I, Chirilă R, Matei IA, Ionică AM (2015) Further spreading of canine oriental eyeworm in Europe: first report of Thelazia callipaeda in Romania. Parasit Vectors 8:48

Mihalca AD, Ionică AM, D'Amico G, Daskalaki AA, Deak G, Matei IA, Simonca V, Iordache D, Modrý D, Gherman CM (2016) Thelazia callipaeda in wild carnivores from Romania: new host and geographical records. Parasit Vectors 9:350

Miró G, Montoya A, Hernández L, Dado D, Vázquez MV, Benito M, Villagrasa M, Brianti E, Otranto D (2011) Thelazia callipaeda: infection in dogs: a new parasite for Spain. Parasit Vectors 4:148

Motta B, Schnyder M, Basano FS, Nägeli F, Nägeli C, Schiessl B, Mallia E, Lia RP, Dantas-Torres F, Otranto D (2012) Therapeutic efficacy of milbemycin oxime/praziquantel oral formulation (Milbemax®) against Thelazia callipaeda in naturally infested dogs and cats. Parasit Vectors 5:85

Otranto D, Dutto M (2008) Human thelaziasis, Europe. Emerg Infect Dis 14:647-649

Otranto D, Traversa D (2005) Thelazia eyeworm: an original endo- and ecto-parasitic nematode. Trends Parasitol 21:1-4
Otranto D, Lia RP, Traversa D, Giannetto S (2004a) Thelazia calliapeda (Spirurida, Thelaziidae) of carnivores and humans: morphological study by light and scanning electron microscopy. Parassitologia 45: 125-133

Otranto D, Lia RP, Buono V, Traversa D, Giangaspero A (2004b) Biology of Thelazia callipaeda (Spirurida, Thelaziidae) eyeworms in naturally infected definitive hosts. Parasitology 129(Pt 5):627-633

Otranto D, Testini G, De Luca F, Hu M, Shamsi S, Gasser RB (2005) Analysis of genetic variability within Thelazia callipaeda (Nematoda: Thelazioidea) from Europe and Asia by sequencing and mutation scanning of mitochondrial cytochrome $c$ oxidase subunit 1 gene. Mol Cell Probes 19:306-313

Otranto D, Cantacessi C, Testini G, Lia RP (2006a) Phortica variegata as an intermediate host of Thelazia callipaeda under natural conditions: evidence for pathogen transmission by a male arthropod vector. Int J Parasitol 36:1167-1173

Otranto D, Brianti E, Cantacessi C, Lia RP, Máca J (2006b) The zoophilic fruitfly Phortica variegata: morphology, ecology and biological niche. Med Vet Entomol 20:358-364

Otranto D, Dantas-Torres F, Mallia E, Di Geronimo PM, Brianti E, Testini G, Traversa D, Lia RP (2009) Thelazia callipaeda (Spirurida, Thelaziidae) in wild animals: report of new host species and ecological implications. Vet Parasitol 166:262-267

Otranto D, Cantacessi C, Dantas-Torres F, Brianti E, Pfeffer M, Genchi C, Guberti V, Capelli G, Deplazes P (2015) The role of wild canids and felids in spreading parasites to dogs and cats in Europe. Part II: helminths and arthropods. Vet Parasitol 213:24-37

Otranto D, Colella V, Crescenzo G, Solari Basano F, Nazzari R, Capelli G, Petry G, Schaper R, Pollmeier M, Mallia E, Dantas-Torres F, Lia RP (2016) Efficacy of moxidectin $2.5 \%$ and imidacloprid $10 \%$ in the treatment of ocular thelaziosis by Thelazia callipaeda in naturally infected dogs. Vet Parasitol 227:118-121

Otranto D, Solari Basano F, Pombi M, Capelli G, Nazzari R, Falsone L, Petry G, Pollmeier MG, Lia RP (2019) Effectiveness of the spot-on combination of moxidectin and imidacloprid (Advocate ${ }^{\circledR}$ ) in the treatment of ocular thelaziosis by Thelazia callipaeda in naturally infected cats. Parasit Vectors 12:25

Palfreyman J, Graham-Brown J, Caminade C, Gilmore P, Otranto D, Williams DJL (2018) Predicting the distribution of Phortica variegata and potential for Thelazia callipaeda transmission in Europe and the United Kingdom. Parasit Vectors 11:272

Papadopoulos E, Komnenou A, Thomas A, Ioannidou E, Colella V, Otranto D (2018) Spreading of Thelazia callipaeda in Greece. Transbound Emerg Dis 65:248-252

Paradžik MT, Samardžić K, Živičnjak T, Martinković F, Janjetović Ž, Miletić-Medved M (2016) Thelazia callipaeda - first human case of thelaziosis in Croatia. Wien Klin Wochenschr 128:221-223

Rossi L, Bertaglia P (1989) Presence of Thelazia callipaeda Railliet and Henry, 1910, in Piedmont, Italy. Parassitologia 31:167-172

Ruytoor P, Déan E, Pennant O, Dorchies P, Chermette R, Otranto D, Guillot J (2010) Ocular thelaziosis in dogs, France. Emerg Infect Dis 16:1943-1945

Tasić-Otašević S, Gabrielli S, Trenkić-Božinović M, Petrović A, Gajić B, Colella V, Momčilović S, Cancrini G, Otranto D (2016) Eyeworm infections in dogs and in a human patient in Serbia: a one health approach is needed. Comp Immunol Microbiol Infect Dis 45:20-22

Vieira L, Rodrigues FT, Costa A, Diz-Lopes D, Machado J, Coutinho T, Tuna J, Latrofa MS, Cardoso L, Otranto D (2012) First report of canine ocular thelaziosis by Thelazia callipaeda in Portugal. Parasit Vectors 5:124 